\title{
Research on the effect of government subsidies on productivity of IOT enterprises_-An Empirical Study Based on Data of Listed Companies from 2016 to 2018
}

\author{
Shuyang $\operatorname{Nan}^{1, a}$ \\ ${ }^{1}$ Beijing Jiaotong University, No.3, Shangyuan Village, Haidian District, Beijing, China \\ ahappynsy6239@163.com
}

Keywords: Government subsidies, IOT, FTP.

\begin{abstract}
In recent years, the rapid development of the IOT industry is closely related to government subsidies. This paper conducts an empirical research based on data of listed companies from 2016 to 2018 by panel fixed effect model to test the effect of government subsidies on total factor productivity of listed companies. The empirical results show that government subsidies significantly promote the total factor productivity of IOT listed companies and show a significant inhibitory effect after a oneyear lag. Finally, the paper discusses the corresponding countermeasures and Suggestions, in order to provide beneficial ideas for the development of China's IOT industry.
\end{abstract}

\section{Introduction}

Government subsidy is an important source of funds for the rapid development of the IOT industry in China. As a strategic emerging industry, the IOT industry has the characteristics of large investment scale and high risk. It is difficult to achieve leapfrog development only by internal investment and capital accumulation. In the macro background of the government's efforts to encourage enterprise independent innovation in China, the government's financial subsidies to the IOT industry mainly focus on the transformation of enterprise scientific and technological achievements and technical services, enterprise independent innovation and industrialization development. The vigorous development of the Internet of things industry is inseparable from various supportive policies. Central and local governments regard the IOT industry as an important driving force for the economic development of their regions, granting tax incentives, setting up special funds and establishing industrial parks, etc. However, there are relatively few studies on whether and to what extent the huge government subsidies have played a positive role in improving the productivity of IOT enterprises and how to play a better role, and the conclusions are not completely consistent. This paper intends to carry out in-depth exploration in order to provide beneficial ideas for the better and faster development of the IOT industry.

\section{Literature review}

Reviewing relevant literature, scholars have different views on the effectiveness of government subsidies. Relevant research conclusions of foreign scholars are mainly divided into three categories. First, government subsidies promote enterprises' innovation activities. For example, Hitaj. (2013) found that the cash subsidy policy provided by the federal government based on output plays an important role in promoting the development of the wind power industry based on the data from 1998 to 2007. Second, there are differences in the effects of government subsidies on enterprises' innovation activities. For example, Luigietal. (2010) put forward that similar policies have different effects in different countries due to different situations in eastern European countries. Third, government subsidies have no impact on enterprises' innovation activities, or even have a negative impact. For example, based on the data of Irish manufacturing enterprises, Holgeretal. (2007) empirically analyzed the relationship between $R \& D$ subsidy of government and $R \& D$ input of enterprise, and found that large-scale R\&D subsidy had crowding-out effect on enterprises' own R\&D input. 
Domestic studies also have three conclusions. Through empirical analysis of 30 IOT listed companies from 2009 to 2011, Jiafeng He (2012) found that government subsidies had a small positive impact on R\&D input, output contribution and financing capacity. However, Fangzhao Zhou et al. (2013) took 27 IOT listed companies as research objects, and their empirical conclusions from 2009 to 2011 showed that government subsidies did not improve the productivity of these companies. Wang Qiuming Wang (2014) found that the government subsidies didn't promote the R\&D input of enterprises due to the difficulty of government supervision of enterprise behavior and the weakness of government punishment based on the data from 2002-2011 of 80 listed companies in strategic emerging industries Other scholars believed that there is uncertainty in the effect of government subsidies. For example, Min Shao et al. (2012) found that when the intensity is less than a certain threshold, government subsidies can significantly promote the improvement of enterprises' productivity. When the intensity gradually increases at the critical level, the promoting effect also changes from significant to insignificant, but its inhibiting effect on enterprise productivity changes also gradually emerges. When the level of government subsidy increases to more than another threshold, government subsidy significantly inhibits the improvement of enterprise productivity.

The rich research results of many scholars have laid a solid foundation for the research of this paper, but the conclusions are not completely consistent, so this paper will carry out further research.

\section{Model selection and empirical results}

\subsection{Research object description}

Referring to the division of IOT concept stocks by Wind , the mainstream capital market data center, and eliminating the companies whose main businesses have little to do with IOT technology, this paper selects the financial data of 24 IOT listed companies such as " GOHIGH DATA NETWORKS TECHNOLOGY " from 2016 to 2018 as the research sample.

\subsection{Calculation of TFP}

There are many calculation methods for total factor productivity, and the Solow Residual is adopted in this paper:

$$
\mathrm{LNY}_{\mathrm{i}, \mathrm{t}}=\beta_{0}+\beta_{1} * \mathrm{LNL}_{\mathrm{i}, \mathrm{t}}+\beta_{2} * \mathrm{LNK}_{\mathrm{i}, \mathrm{t}}+\beta_{3} * \mathrm{LNM}_{\mathrm{i}, \mathrm{t}}+\mu_{\mathrm{i}, \mathrm{t}} .
$$

In the above formula, $Y_{i, t}$ represents the total output of the ith IOT listed company in the year $\mathrm{t}$, which is measured by the sum of prime operating revenue and change in inventory in the year. $L_{i, t}$ represents the labor input of the ith IOT listed company in the year $t$, which is measured by "cash outflow to pay employees' wages" in the cash flow statement. $K_{i, t}$ represents the capital input of the ith IOT listed company in the year $t$. Due to the lack of relevant data, this paper measures year-end fixed assets in the balance sheet. $M_{i, t}$ represents the input of various other factors in the production process of the ith IOT listed company in the year $t$, which is measured by the item "cash outflow from purchasing products and services" in the cash flow statement. i stands for 1 to 40. $t$ stands for 2016 to 2018. $\beta_{1}, \beta_{2}$ and $\beta_{3}$ represent the output elasticity of L, M and K. $\mu_{i, t}$ is random disturbance term.

Using the data of listed companies and the measurement software Stata, the regression of equation 1 was conducted by panel fixed effect method. The results are shown in table 1 . The residual is the estimated value of total factor productivity of each listed company in 3 years, as shown in table 2 .

Table 1 regression results of equation 1

\begin{tabular}{c|c|c}
\hline coefficient & value & t value \\
\hline$\beta_{0}$ & $2.744759^{* * *}$ & 4.04 \\
\hline$\beta_{1}$ & 0.0882547 & 0.28 \\
\hline$\beta_{2}$ & 0.2069426 & 0.51 \\
\hline$\beta_{3}$ & $0.1686405^{* *}$ & 2.19 \\
\hline$R^{2}$ & 0.80745912 & \\
\hline Prob>F & 0.0000 & \\
\hline
\end{tabular}

Note $: *, * *, * * *$ represent significant at the level of $10 \%, 5 \%$, and $1 \%$ 
Table 2 TFP estimates of listed IOT companies (2016-2018)

\begin{tabular}{c|c|c|c|c|c|c|c}
\hline Order & 2016 & 2017 & 2018 & Order & 2016 & 2017 & 2018 \\
\hline 1 & 0.968797 & 0.783812 & 0.849024 & 13 & 0.070034 & -0.10955 & -0.36109 \\
\hline 2 & 0.214741 & 0.013965 & 0.199089 & 14 & 0.135041 & 0.184197 & 0.044636 \\
\hline 3 & -0.28672 & -0.66274 & -0.70287 & 15 & 0.006493 & 0.211238 & 0.309654 \\
\hline 4 & 0.86929 & 0.111547 & 0.408853 & 16 & -0.05765 & -0.14856 & -0.20289 \\
\hline 5 & 0.697597 & 0.185639 & 0.387911 & 17 & 0.25009 & 0.048928 & -0.12624 \\
\hline 6 & 0.485429 & 0.245489 & 0.059432 & 18 & -0.78727 & -0.73064 & -0.88652 \\
\hline 7 & 0.359863 & 0.495837 & 0.557933 & 19 & -0.37232 & -0.80406 & -0.65818 \\
\hline 8 & 0.584073 & -0.02224 & 0.273873 & 20 & -2.19523 & -0.8351 & -0.86039 \\
\hline 9 & -0.13246 & -0.23145 & -0.19541 & 21 & 1.500215 & 1.228806 & 1.17186 \\
\hline 10 & 0.157845 & 0.209523 & 0.535348 & 22 & 0.641208 & 0.095675 & -0.48585 \\
\hline 11 & -0.20801 & -0.33024 & -0.45665 & 23 & 0.402802 & 0.002758 & 0.17061 \\
\hline 12 & -0.24175 & -0.42684 & -0.29665 & 24 & -0.69411 & -0.97708 & -0.64242 \\
\hline
\end{tabular}

\subsection{The effect of government subsidies on total factor productivity}

According to relevant theories and existing studies, in addition to government subsidies, enterprise growth and enterprise scale also have a greater impact on TFP. Generally speaking, the better the growth prospects of enterprises, the stronger the motivation of the owners, operators and workers of enterprises to engage in innovation activities, and the higher TFP. The larger the scale of the enterprise, on the one hand, the enterprise is more likely to be able to earn more excess profits to support R\&D activities of the enterprise, which is conducive to improving the production efficiency of the enterprise; On the other hand, in order to maintain monopoly power, enterprises will have greater incentive to carry out innovative research and development. Accordingly, the model is built as shown in equation 2:

$$
\mathrm{TFP}_{\mathrm{i}, \mathrm{t}}=\mathrm{a}+\sum_{\mathrm{j}=0}^{2} \mathrm{~b} * \mathrm{j} * \mathrm{SUB}_{\mathrm{i}, \mathrm{t}-\mathrm{j}}+\mathrm{c} * \mathrm{SCA}_{\mathrm{i}, \mathrm{t}}+\mathrm{d} * \mathrm{DEV}_{\mathrm{i}, \mathrm{t}}+\mu_{\mathrm{i}, \mathrm{t}} .
$$

In the above formula, $S U B_{i, t}$ represents intensity of government subsidy of the ith IOT listed company in the year $\mathrm{t}$, which is measured by the ratio of "non-operating income -- government subsidy" in the annual income statement to prime operating revenue. $S C A_{i, t}$ represents the scale of the ith IOT listed company in the year $t$, which is measured by growth rate of the total assets. $D E V_{i, t}$ represents the growth situation of the ith IOT listed company in the year $t$, which is measured by growth rate of operating revenue. To investigate the lagging effect of government subsidies, items with a lag of 1 year and a lag of 2 years are added. a, b, c, and d are coefficients.

Using the estimated value of TFP and other relevant data of the listed company, the regression of equation 2 was conducted. Considering the possible lag effect of government subsidies, the panel fixed effect (passed by Hausman test) was conducted twice by adding first phase lag term. The empirical results are shown in table 3:

Table 3 Regression results of the effect of government subsidies on TFP

\begin{tabular}{c|c|c}
\hline Variable & Model I & Model II \\
\hline $\mathrm{a}$ & -3.91345 & $-13.63814^{* * *}$ \\
\hline$S U B$ & 1.086458 & -0.2784111 \\
\hline$S U B_{-1}$ & & $1.420386^{* * *}$ \\
\hline$S C A$ & 0.4067611 & 0.0457351 \\
\hline$D E V$ & 0.1280561 & 0.85264506 \\
\hline$R^{2}$ & 0.68488977 & 0.0003 \\
\hline Prob>F & 0.0269 & \\
\hline
\end{tabular}

Note :*, $* *, * * *$ represent significant at the level of $10 \%, 5 \%$, and $1 \%$

It can be seen from table 3 that government subsidies have a significant promoting effect on the improvement of production efficiency of IOT listed companies in the current period. However, the government subsidy has a significant restraining effect on the improvement of total factor productivity of listed companies in the lag period. 


\section{Policy recommendations}

In order to make government subsidies effective and better promote the development of China's IOT industry, this paper believes that, first, combining the characteristics of the development of the IOT, allocate subsidy funds according to different stages and fields, and timely adjust the duration and scale of subsidies according to the changing situation, so as to improve the incentive effect of government subsidies on industrial R\&D. Second, give full play to the guiding role of the government in the allocation of public resources, and study and formulate policies to support the IOT, including finance, land, taxation, government procurement and talents.

\section{References}

[1] Claudia Hitaj, Wind power development in the United States, Journal of Environmental Economics andManagement,vol.65 ,pp. 394- 410, 2013.

[2] D. L., T.E., Economic analysis of different supporting policies for the production of electrical energy by solar photovoltaics in eastern European Union countries, Energy Policy, vol 38, pp.4011-4020, 2010.

[3] Jiafeng He, A study on the effectiveness of financial subsidy policies in China's Internet of things industry -- based on empirical data of listed companies, Journal of central university of finance and economics. Vol.9,pp.12-16, 2012.

[4] Fangzhao Zhou, Tax subsidies, venture capital and the productivity of high-tech enterprises -empirical evidence from listed IOT companies in China. Soft science, vol.3, pp.100-105,2013.

[5] Qiuming Wang, Government subsidy and enterprise behavior in strategic emerging industries -based on dynamic game analysis under government regulation, Public Finance Research, vol.7, pp.43-53, 2014.

[6] Ming Shao, Government subsidy and enterprise productivity -- based on the empirical analysis of China's industrial enterprises, Chinese industrial economy, vol.7, pp.70-80, 2012.

[7] Xiaozhong Li, Research on the impact of government subsidies on productivity of IOT enterprises, Chinese soft science, vol.2, pp.105-110, 2016. 